\title{
Kabuverdianu no sistema educativo em Cabo Verde e o seu status em relação ao português ${ }^{1}$
}

\author{
Ronny Beckert ${ }^{2}$ \\ Romanisches Seminar, Universidade de Heidelberg, Heidelberg, Alemanha
}

Resumo: Este artigo analisa o discurso sobre a introdução do kabuverdianu no sistema educativo cabo-verdiano dominado pela língua oficial, o português. Também se analisam os efeitos do ensino da língua não-L1 nos participantes assim como a percepção da relação entre português e kabuverdianu (status e prestígio) e a questão da escrita do kabuverdianu. Enquanto a UNESCO vem exigindo o direito de o ensino ocorrer na própria L1, os projetos para integrar o kabuverdianu no sistema educativo cabo-verdiano são discutidos de forma controversa pelos falantes. $O$ estudo é baseado nas respostas de um questionário online, bem como nos comentários dos leitores em artigos disponíveis online. Os apoiantes enfatizam o anseio por um melhor desempenho de aprendizagem dos alunos e a valorização da própria L1. A falta de uma norma crioula bem aceita e o receio de que Cabo Verde se isole (linguisticamente) são razões contra a introdução do crioulo nas escolas cabo-verdianas.

Palavras-chave: Kabuverdianu; Língua de ensino; Norma; Cabo Verde; ALUPEC.

Title: Kabuverdianu in the education system in Cape Verde and its status in relation to Portuguese

Abstract: This article analyzes the discourse on the introduction of Kabuverdianu into the education system of Cape Verde which is dominated by Portuguese, the country's official language. It also analyzes the effects of non-L1 language teaching on the participants as well as the perception of the relationship between Portuguese and Kabuverdianu (status and prestige), as well as the question of an orthographic script of Kabuverdianu. While the UNESCO is constantly demanding the right of education in L1, projects for integrating Kabuverdianu into the Cape Verdean education system are controversially discussed by its speakers. This study is based on responses to an online questionnaire and on comments from readers of online articles. The supporters emphasize the expected better learning performance of students and the valorization of the L1. The lack of an accepted Creole norm and the fear that Cape Verde will (linguistically) isolate itself are reasons against the introduction of Creole into Cape Verdean schools.

Keywords: Kabuverdianu; Language of instruction; Norm; Cabo Verde; ALUPEC.

\footnotetext{
${ }^{1}$ Agradeço a Thaís Dias de Castilho Ehrler pela leitura cuidadosa do texto.

2 Doutorando em Linguística Portuguesa (Universidade de Heidelberg). Docente e assistente de investigação do Departamento dos Estudos Românicos (Romanisches Seminar) da Universidade de Heidelberg. Orcid: https://orcid.org/0000-0002-2408-3192. E-Mail: ronny.beckert@rose.uni-heidelberg.de.
} 


\section{Introdução}

Cabo Verde, antiga colônia portuguesa e país independente desde 1975 , situa-se no oceano Atlântico e consiste nas ilhas de Santo Antão, São Vicente, Santa Luzia (não povoada), São Nicolau, Sal, Boa Vista (formando as ilhas do Barlavento) e nas ilhas de Brava, Fogo, Santiago e Maio (formando as ilhas de Sotavento). O país tem cerca de 556.000 habitantes em 2020 conforme as projeções demográficas do Instituto Nacional de Estatística de Cabo Verde (INECV, 2013, p. 24). A única língua oficial é o português. A questão da língua oficial está regularizada no primeiro parágrafo do artigo 9 da Constituição da República de Cabo Verde ("É língua oficial o Português."), apesar de o artigo ser intitulado - propositadamente ou por acidente - "Línguas oficiais". No segundo parágrafo, o Estado compromete-se a promover as condições para a oficialização do crioulo cabo-verdiano: "O Estado promove as condições para a oficialização da língua materna cabo-verdiana, em paridade com a língua portuguesa." No terceiro parágrafo, observa-se a necessidade de cada cidadão cabo-verdiano conhecer e usar - outra vez usando o plural - as línguas oficiais: "Todos os cidadãos nacionais têm o dever de conhecer as línguas oficiais e o direito de usá-las" (BOLETIM OFICIAL, 2010, I série, n.o 17).

Embora as estatísticas oficiais não registrem o número de falantes de crioulo ou de português, assume-se que o crioulo cabo-verdiano (também chamado kriolu ou kabuverdianu) é a língua falada dominante no país (BAPTISTA, 2013; LANG, 2013; SWOLKIEN, 2013), cuja população é maioritariamente bilíngue, sendo o português, muitas vezes, a segunda língua (LOPES, 2011, p. 494). Kabuverdianu, como todas as outras línguas naturais, apresenta variações diastráticas, diafásicas, diatópicas etc. É geralmente dividido em dois grupos principais de variedades: as variedades das ilhas de Barlavento (Sal, Boa Vista, São Nicolau, São Vicente, Santo Antão) e as variedades das ilhas de Sotavento (Maio, Santiago, Fogo, Brava) (SWOLKIEN, 2004, p. 171). Porém, ainda não foi estabelecida nenhuma variedade de referência que fosse igualmente aceita por todos os falantes do kabuverdianu.

A relação entre português e crioulo em Cabo Verde é frequentemente retratada como uma relação diglóssica, embora os autores nem sempre expliquem qual o entendimento do termo 'diglossia' utilizado. Lembra-se que a definição do conceito de 'diglossia', na sua origem, elaborado por Ferguson (1959), refere-se à relação entre duas variedades de uma língua, uma das quais sendo a variedade alta (high variety) e a outra, a variedade baixa (low variety). Observa-se nesta constelação, que Ferguson (1959) considera como sendo uma situação estável, uma repartição funcional de usos. A variedade alta é usada em situações de comunicação consideradas de maior prestígio pela sociedade (por exemplo, na igreja, discurso político, universidade, noticiários, jornais, poesia), enquanto a variedade baixa é usada em situações de comunicação de menor prestígio (por exemplo, em instruções aos empregados, conversas com a família, amigos e colegas, literatura popular) (FERGUSON, 1959, p. 327-332). Fishman (1967) ampliou o conceito inicial, introduzindo a ideia de que duas línguas diferentes não precisam estar relacionadas. Além disso, Fishman (1967, p. 34) aponta para a distinção entre o termo 'bilinguismo', que é uma caracterização do comportamento linguístico individual, e o termo 'diglossia', que apresenta uma caracterização da organização linguística 
a nível sociocultural. ${ }^{3}$

Durante o período colonial em Cabo Verde, o português era dominado corretamente tanto na língua oral quanto na escrita apenas por uma pequena minoria que "por via de regra, o aprendeu na escola, e que dele se serve normalmente em situações formais, como se serviria de outras línguas de grande circulação que tivesse aprendido a falar e a escrever nas mesmas circunstâncias" (DUARTE, 1998, p. 22). Assim como em outros países colonizados por europeus, a língua do colonizador, um meio de promoção social, adquiriu maior prestígio em relação ao crioulo, a língua mais falada (DUARTE, 1998, p. 23-24).

Entretanto, a relação entre o português e o crioulo em Cabo Verde, hoje em dia, já não pode ser limitada a um conceito rígido de diglossia, em que cada língua está sujeita a uma distribuição precisa de funções. Os respectivos domínios linguísticos não são mais ocupados por apenas uma língua. Seus escopos de aplicação estenderam-se: o português é agora também utilizado em situações de conversação informal e íntima, nos quais o crioulo era outrora a língua principal utilizada, e o crioulo é utilizado em situações de conversação mais formais, que antes eram reservadas exclusivamente ao português (LOPES, 2011, p. 494). Em seu estudo sobre hábitos e atitudes de comunicação em relação ao português e ao kabuverdianu, especialmente em falantes jovens, Lopes (2011) conclui:

Diferentemente do que é apontado na literatura como comum nessas situações, os resultados, quer em termos de uso quer em termos de atitudes, apontam para a manutenção das duas línguas com resolução do conflito diglóssico por via da construção de um bilinguismo sem diglossia ou horizontal; este tipo de bilinguismo caracteriza-se pela igualdade de estatuto e de funcionalidade das duas línguas, mas em que certamente a LP [língua portuguesa, R.B.] teria vantagens, como língua de comunicação internacional (LOPES, 2011, p. 494).

A língua do ensino em Cabo Verde continua a ser o português, a língua do antigo colonizador, embora aulas-piloto bilíngues (português/crioulo) tenham sido introduzidas em algumas escolas de ensino fundamental no ano letivo 2013/2014 sob a orientação de A. J. Cardoso, demonstrando efeitos positivos no desempenho dos alunos (ROSA, 2017, p. 7-8). Desde a pré-escola até a faculdade, porém, o crioulo não está integrado no sistema educativo de forma extensa e contínua. Essa é a realidade linguística em muitos países crioulófonos nos quais uma língua europeia (francês, inglês, português etc.) é até hoje a única língua oficial, salvo algumas exceções, atribuindo ao crioulo local um estatuto cooficial como, por exemplo, em Haiti (francês, crioulo de Haiti) ou nas Seicheles (francês, inglês, crioulo de Seicheles). Além disso, as línguas crioulas de base lexical europeia muitas vezes carregam o estigma de serem vistas como versões corrompidas das línguas dos respectivos países europeus colonizadores e de não serem línguas 'verdadeiras' ${ }^{4}$, de modo que possuem pouco prestígio e que somente a aquisição de antigas línguas coloniais foi e é considerada desejável (VELUPILLAI, 2015, p. 4546). Apenas gradualmente observam-se tentativas modestas para integrar as línguas crioulas

\footnotetext{
${ }^{3}$ Cf. Sinner (2014), que retrata a história de conceitos básicos da linguística de contato.

${ }^{4}$ Esta posição negativa, aliás, não é nada estranha às línguas românicas se pensarmos nos séculos passados quando elas "eram consideradas uma degenerescência do latim" (DUARTE, 1998, p. 27-28).
} 
nos sistemas educacionais dos países crioulófonos. Esse processo é, em muitos casos, acompanhado por debates polêmicos, nos quais os próprios falantes das línguas crioulas se pronunciam contra a introdução do crioulo como língua de ensino (MIGGE; LÉGLISE; BARTENS, 2010, p. 2-3).

Constata-se que, em Cabo Verde, não é possível determinar com exatidão qual é a língua dominante e qual é a língua minoritária. A avaliação depende sempre de vários fatores, principalmente da situação comunicativa. O crioulo cabo-verdiano é sem dúvida a língua dominante na comunicação oral, mas que se torna uma língua com pouca visibilidade em alguns domínios linguísticos (de prestígio, sobretudo), principalmente no sistema educativo, na visibilidade como língua escrita no espaço público ou na escrita em geral, nos quais o português predomina. ${ }^{5}$

Neste artigo, pretende-se oferecer uma análise qualitativa do discurso em Cabo Verde a respeito da introdução do crioulo nas escolas cabo-verdianas, representando os argumentos e as opiniões contra e em prol da introdução do crioulo no sistema educativo. ${ }^{6}$ Além disso, analisa-se se o fato de o português não ser a L1 da maioria dos participantes teve um impacto no próprio sucesso escolar. Abordamos também a questão da escrita do kabuverdianu, que não é de menor importância quando se trata da sua introdução como língua de ensino. Finalmente, analisa-se a relação entre o crioulo e o português, avaliada pelos informantes.

\section{Metodologia e perfil dos participantes}

Os dados em que se baseia a presente análise provêm de duas fontes. Por um lado, foi elaborado um questionário online e, por outro, foi compilado um pequeno corpus de textos jornalísticos disponíveis na internet, com os comentários dos seus leitores. O questionário consiste em perguntas fechadas e abertas, 43 no total, e está disponível tanto em português (Cabo Verde), quanto em francês (Reunião), levando-se em conta, para este artigo, apenas as respostas em relação a Cabo Verde. O questionário online foi escolhido como método, pois proporciona acesso rápido a muitos informantes potenciais a baixo custo. $O$ questionário foi distribuído em redes sociais durante o período de agosto a outubro de 2018. Com a resposta afirmativa à segunda pergunta do questionário, a declaração de consentimento, os participantes concordaram com o uso anônimo de suas respostas para fins científicos. Caso não estivessem de acordo, o questionário era automaticamente encerrado. Não há dúvida de que só se conseguiu alcançar uma pequena parte da população cabo-verdiana, principalmente as pessoas que têm acesso às respectivas redes sociais e que as utilizam frequentemente. Por outro lado, o método garante o anonimato dos informantes e supõe-se que se reduzem os efeitos do paradoxo de observador.

\footnotetext{
${ }^{5}$ Durante minha primeira estadia em Cabo Verde, em 2014, ouvi crioulo em toda parte, mas era quase inexistente como língua usada na sua forma escrita no espaço público, em cartazes, placas etc.

${ }^{6}$ Uma parte desta análise está em fase de publicação em Beckert e Schröder (no prelo) num estudo comparando as atitudes dos habitantes da ilha de Reunião (território ultramarino da França) e de Cabo Verde quanto à introdução dos crioulos nas escolas.
} 
Quadro 1 - Perfil dos participantes

\begin{tabular}{|c|c|c|}
\hline Participantes & 48 & \\
\hline Sexo & $\begin{array}{ll}f & m \\
31 & 17\end{array}$ & \\
\hline Idade & $21-67$ anos & \\
\hline $\begin{array}{l}\text { Ilha de } \\
\text { residência } \\
\text { atual }\end{array}$ & $\begin{array}{l}\text { Santiago } \\
\text { São Vicente } \\
\text { Santo Antão } \\
\text { Maio } \\
\text { Sal }\end{array}$ & $\begin{array}{c}40 \\
3 \\
3 \\
1 \\
1\end{array}$ \\
\hline $\begin{array}{l}\text { Língua(s) } \\
\text { materna(s) }\end{array}$ & $\begin{array}{l}\text { Crioulo } \\
\text { Português } \\
\text { Português e }\end{array}$ & $\begin{array}{c}44 \\
3 \\
0 \\
1\end{array}$ \\
\hline
\end{tabular}

Fonte: o autor.

Participam no inquérito 48 pessoas $^{7}$, residindo maioritariamente em Santiago, ilha principal do arquipélago, com uma participação feminina quase duas vezes superior à masculina, mas bem distribuída de acordo com os grupos etários (quadro 1). A L1 da maioria dos participantes é o crioulo cabo-verdiano (40), ou seja, uma das suas variedades; dois participantes deste grupo indicam duas ou três variedades do crioulo como L1. Das três pessoas que indicaram o português como L1, uma vem do Brasil, uma de Portugal e uma de Cabo Verde. Um único participante indicou ter duas L1, crioulo e português.

O nível de educação dos participantes é geralmente elevado: 45 terminaram o ensino médio e 33 têm um diploma universitário, que, evidentemente, não representa a estrutura social de Cabo Verde. Por isso, os resultados a seguir refletem antes a opinião de uma elite educada, pois uma grande parte dos participantes trabalha no setor educacional.

Deve-se notar que os participantes, devido ao seu perfil linguístico e ao fato de a maioria ter passado pelo sistema educativo cabo-verdiano, representam vozes válidas para expressar opiniões sobre a introdução do crioulo nas escolas. Além disso, quase todos usam o crioulo no seu dia-a-dia (figura 1, múltiplas respostas possíveis).

Figura 1 - As línguas usadas no dia-a-dia

1. Que língua(s) usa no dia-a-dia?

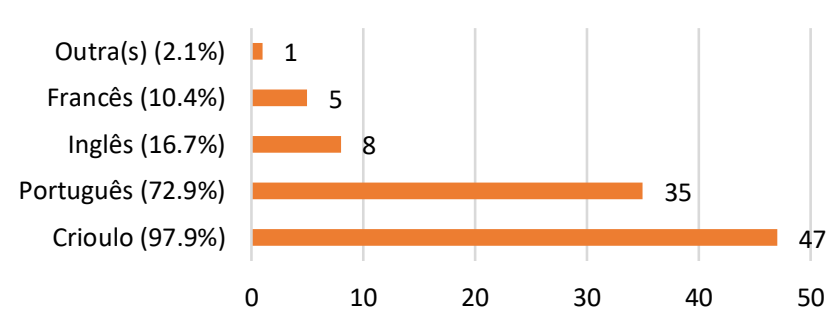

Fonte: o autor.

\footnotetext{
${ }^{7}$ No estudo de Beckert e Schröder (no prelo), foram considerados 47 participantes de Cabo Verde. A diferença explica-se pelo fato que o questionário permaneceu acessível depois de outubro de 2018. Uma pessoa deparouse com o questionário e respondeu às perguntas apenas em janeiro de 2019.
} 
A tabela 1 mostra as autoavaliações dos participantes sobre suas habilidades de falar e escrever tanto em português, quanto em crioulo. Torna-se evidente que a maioria das habilidades em português (falar e escrever) são marcadas como 'bem' e 'muito bem' (mais de 93,5\% cada). As opções de resposta 'bem' e 'muito bem' para a autoavaliação relativa à capacidade de falar crioulo somam até $100 \%$. No entanto, a habilidade de escrever em crioulo é, em média, pior classificada do que em português. A razão para isso é que os informantes eram alfabetizados exclusivamente em português com manuais escolares em português (cf. tabela 2, abaixo). O português foi a única língua de ensino para $96 \%$ dos 48 participantes. Para $85 \%$ ou 46 participantes, entre aqueles que indicaram o português como única língua de ensino, o português não foi a primeira língua $(L 1)^{8}$, mas o crioulo. ${ }^{9}$

Tabela 1 - Competências linguísticas

\begin{tabular}{lclllllr}
\hline 2. Sabe falar português? & \multicolumn{2}{c}{$\begin{array}{c}\text { 4. Sabe escrever em } \\
\text { português? }\end{array}$} & \multicolumn{2}{c}{ 6. Sabe falar crioulo? } & \multicolumn{2}{c}{$\begin{array}{c}\text { 8. Sabe escrever em } \\
\text { crioulo? }\end{array}$} \\
\hline - muito bem & $62,50 \%$ & - muito bem & $60,42 \%$ & - muito bem & $89,58 \%$ & - muito bem & $50,00 \%$ \\
- bem & $31,25 \%$ & - bem & $35,42 \%$ & - bem & $10,42 \%$ & - bem & $33,33 \%$ \\
- suficiente & $6,25 \%$ & - suficiente & $4,17 \%$ & - suficiente & $0,00 \%$ & - suficiente & $12,50 \%$ \\
- mal & $0,00 \%$ & - mal & $0,00 \%$ & - mal & $0,00 \%$ & - mal & $4,17 \%$ \\
- muito mal & $0,00 \%$ & - muito mal & $0,00 \%$ & - muito mal & $0,00 \%$ & - muito mal & $0,00 \%$ \\
& $\left(n=48^{10}\right)$ & & $(n=48)$ & $(n=48)$ & $(n=48)$ \\
\hline
\end{tabular}

Fonte: 0 autor.

A fim de analisar mais opiniões a respeito da introdução do crioulo nas escolas, compilamos um corpus de artigos de jornal que foram publicados entre 2014 e 2018 e que estão disponíveis online nas respetivas páginas de internet desses jornais. Estávamos particularmente interessados nas discussões dos leitores que, em linha, seguem geralmente abaixo dos artigos, contudo mais uma vez, não podemos assumir que os comentários dos leitores representem um recorte da sociedade cabo-verdiana. Consideramos artigos publicados nos jornais cabo-verdianos Expresso das Ilhas (EDI), A Nação (AN) e Notícias do Norte (NN) ou no site de Rádio Televisão de Cabo Verde (RTC). O perfil dos autores dos comentários dos leitores não pode ser determinado.

Com base nos temas evocados no corpus, deduzimos as principais categorias não só de argumentos a favor e contra o crioulo na escola (vantagens educacionais diferentes versus inferioridade, separação das línguas, falta de um padrão), mas também o tema de 'insegurança linguística'.

\footnotetext{
${ }^{8}$ Usa-se o termo 'primeira língua' ou 'L1' para evitar o termo controverso 'língua materna', ainda que usamos este último no questionário sendo o termo mais comum em conversas cotidianas fora da linguística.

${ }^{9}$ Observa-se aqui uma heterogeneidade nas respostas dos informantes, a saber: à pergunta $\mathrm{n}^{\circ} 12$ (" $\mathrm{A}$ língua de ensino é/foi a sua língua materna?") sete informantes responderam por "sim", embora apenas quatro deles indicassem o português como L1 no início do questionário (na seção "Dados pessoais"); os outros três indicaram uma ou mais variedades do crioulo como L1.

${ }^{10}$ Visto que nem todos os participantes preencheram o questionário até o fim, nas tabelas e quadros está sempre indicado o número total das respostas dadas (n).
} 


\section{A língua primeira na escola: um discurso eterno}

Na sua Conferência Plenária em 1999, a UNESCO aprovou mais uma resolução sobre a implementação de uma política linguística para o mundo baseada no multilinguismo e exprime nela a recomendação aos países membros de "promote, through multilingual education, democratic access to knowledge for all citizens, whatever their mother tongue, and build linguistic pluralism" (UNESCO, 2000, p. 35). Desde 2000, a UNESCO celebra no dia 21 de fevereiro o "Dia Internacional da Língua Materna". Em 2017, a então diretora-geral da UNESCO, Irina Bokova, sublinha a importância do ensino em língua materna:

Educação e informação na língua materna são essenciais para melhorar o aprendizado, desenvolver a confiança e a autoestima, que estão entre os motores mais poderosos do desenvolvimento. Somos seres da linguagem [...]. Culturas, ideias, sentimentos e até mesmo aspirações por um mundo melhor são apresentados em primeiro lugar e sempre em uma língua específica, com palavras específicas. Essas línguas carregam valores e visões de mundo que enriquecem a humanidade. Valorizar esses idiomas permite aumentar o leque de futuros possíveis e fortalece a energia necessária para os alcançar (UNESCO, 2017, tradução nossa). ${ }^{11}$

Contudo, já em 1953, a UNESCO publicou um relatório que defende o uso da primeira língua de uma criança na escola (BAPTISTA; BRITO; BANGURA, 2010, p. 277). Duarte (1998) apoia também a utilização do crioulo na escola:

[...] há a necessidade de escolarizar as crianças na língua materna, diminuindo a percentagem de insucesso escolar devido à utilização de uma língua, a portuguesa, que é estranha à prática social da maioria esmagadora das crianças e adolescentes das nossas escolas, sobretudo os dos meios rurais (DUARTE, 1998, p. 205).

Nos subitens seguintes, veremos se a situação em países africanos, nomeadamente em Cabo Verde, e se as opiniões no arquipélago quanto ao ensino em língua materna coincidem com a visão da UNESCO.

\section{A questão da língua de ensino em países africanos}

Em muitos Estados europeus, está fora de cogitação que a língua majoritariamente falada pela população, que é geralmente a língua primeira dos habitantes, não seja a língua de ensino. ${ }^{12}$ No entanto, em muitos outros países do mundo, a L1 da população não é

\footnotetext{
11 Original: “L'éducation et l'information dans la langue maternelle est primordial [sic] pour améliorer les apprentissages, développer la confiance et l'estime de soi, qui sont parmi les plus puissants moteurs de développement. Nous sommes des êtres de langage [...]. Les cultures, les idées, les sentiments et mêmes les aspirations à un monde meilleur se présentent d'abord et toujours à nous dans une langue précise, avec des mots particuliers. Ces langues portent des valeurs et des visions du monde qui enrichissent l'humanité. Valoriser ces langues permet d'élargir l'éventail des futurs possibles, et de renforcer l'énergie nécessaire pour y parvenir." ${ }^{12}$ Estamos conscientes do fato de que, nos países europeus, existem várias línguas autóctones (minoritárias) que têm diferentes estatutos e papéis nos sistemas educativos (cf. HERRERAS, 2014).
} 
necessariamente a língua de ensino, como por exemplo em muitos países africanos nos quais, por sua história colonial e por escolhas políticas após as independências, a língua de ensino é a língua do antigo colonizador, que é a segunda ou terceira ou quarta língua etc. para muitos habitantes. A situação linguística nestes países está caraterizada por uma enorme pluralidade etnolinguística (WOLFF, 2016, p. 172-184). Por razões práticas, mas também para evitar conflitos interétnicos que resultariam da escolha de uma língua local, muitos Estados africanos decidiram, após a sua independência na segunda metade do século XX, declarar a língua dos antigos colonizadores a única língua oficial. A escolha de uma língua europeia (francês, inglês, português) como língua nacional oficial também determinou a língua em que os alunos devem passar pelo sistema educativo. O uso de uma língua não-L1 nas escolas africanas levou a enormes desigualdades sociais e a maus resultados na educação escolar:

As práticas educacionais na África fracassaram independentemente dos dois modelos de 'língua-no-ensino' mais comumente utilizados [...]: onde foram mantidos sistemas educacionais baseados no uso exclusivo do idioma do antigo mestre colonial como único meio de instrução, a regra é o desempenho bastante ruim do sistema como um todo. Esta é em grande parte a situação nos chamados países francófonos e lusófonos da África. Isto, entretanto, não é uma surpresa para os especialistas em língua-no-ensino, que sempre sustentaram que a aprendizagem em uma língua estrangeira ou desconhecida simplesmente não pode funcionar para a maioria dos aprendizes (WOLFF, 2006, p. 27, tradução nossa). ${ }^{13}$

Wolff (2006, p. 27) confirma que a questão da língua está totalmente ausente do discurso de desenvolvimento mainstream, no que diz respeito ao discurso sobre questões centrais como a redução da pobreza e o desenvolvimento sustentado para África. Para melhorar a situação, Wolff (2006, p. 31, tradução nossa) defende a implementação sustentável de línguas africanas nos sistemas educativos dos países:

Uma vez que a educação é sobre a abertura de opções de mudança e progresso
social, as elites políticas dos países africanos se veem presas em um dilema que, até
hoje, as fez relutantes em aceitar reformas educacionais que equivaleriam a
mudanças sociais ou rupturas com consequências pouco claras para o equilíbrio de
poder em suas políticas. Uma abordagem mais ampla da política linguística deve ser
orientada com o objetivo de estabelecer o uso de línguas africanas nos domínios
primários dos negócios oficiais do governo nos níveis nacional e provincial ou
regional, ou seja, em todos os domínios legislativos, executivos e jurídicos. Se isso
não for feito, as línguas africanas manterão um status e prestígio baixo e,
posteriormente, isso manterá a marginalização da maioria dos cidadãos e os privará
de opções para mudanças sociais e uma transformação democrática da sociedade. ${ }^{14}$

\footnotetext{
${ }^{13}$ Original: "[E]ducational practices in Africa have failed independent of the two most commonly used languagein-education models [...]: Where educational systems have been retained that are based on the exclusive usage of the language of the former colonial master as the sole medium of instruction, the rule is rather poor performance of the system as a whole. This is largely the situation in the so-called Francophone and Lusophone countries of Africa. This, however, does not come as a surprise to language-in-education experts, who have always maintained that learning in a foreign or unfamiliar language simply cannot work for most learners."

${ }^{14}$ Original: "Since education is about opening up options for social change and progress, the political elites of African countries find themselves trapped in a dilemma which, until this day, has made them somewhat reluctant to accept educational reforms that would amount to social change or ruptures with unclear consequences for
} 
As políticas linguísticas atuais excluem grande parte das sociedades da participação ativa nas decisões políticas tomadas por uma elite pequena, que domina as línguas dos antigos colonizadores (KREMNITZ, 2002, p. 128). Além disso, as atitudes dos falantes em relação à sua própria língua podem ter um impacto nas decisões sociais e políticas:

As atitudes linguísticas, entretanto, provavelmente representem o fator mais crucial que impede a mudança. Muitos daqueles que tomam decisões, assim como a população em geral, não veem pidgins e línguas crioulas como ferramentas legítimas de educação, mas as percebem como derivados corruptos da linguagem padrão (MIGGE; LÉGLISE; BARTENS, 2010, p. 11, tradução nossa). ${ }^{15}$

A seguir, a questão da linguagem no sistema educacional, que acaba de ser descrita sob uma perspectiva científica, é apresentada a partir da perspectiva dos falantes, razão pela qual optamos por citar várias declarações dos informantes do corpus.

Crioulo na escola em Cabo Verde: prós e contras

A maioria dos participantes no inquérito (figura 2) é a favor de o crioulo entrar na escola como língua de ensino ao lado do português (64\%), como disciplina (28\%) ou substituindo o português (2\%), enquanto $6 \%$ acreditam que o crioulo não deve ser usado nas escolas, nem como disciplina, nem como língua de ensino. Na figura 3 vê-se que $56 \%$ dos participantes concordam totalmente e $22 \%$ concordam parcialmente com a declaração da então secretária-geral Irina Bokova de ensinar a $L 1^{16}$, enquanto $20 \%$ rejeitam parcial ou totalmente essa exigência.

the balance of power in their polities. A broader approach to language policy must be targeted with the goal of establishing the use of African languages in the primary domains of official government business on the national and provincial or regional levels, i.e. in all legislative, executive and juridical domains. Failing to do this will maintain low status and prestige for the African languages, and subsequently maintain the marginalisation of the majority of the citizens and bereave them of options for social change and a democratic transformation of Society."

${ }^{15}$ Original: "Language attitudes, however, probably represent the most crucial factor hampering change. Many decision makers, as well as the population at large, do not see P/Cs [Pidgins and Creoles, R.B.] as legitimate tools of education, but perceived them as corrupt derivatives of the standard language".

16 "Educação e informação na língua materna são absolutamente essenciais para aperfeiçoar a aprendizagem e desenvolver a confiança e a autoestima, que estão entre as forças mais poderosas do desenvolvimento" (https://nacoesunidas.org/unesco-dialogo-e-cooperacao-internacional-dependem-do-respeito-a-diversidadelinguistica, Acesso em: 10 maio 2020). 
Figura 2 - O crioulo na escola

17. Gostaria de ver o crioulo na escola...

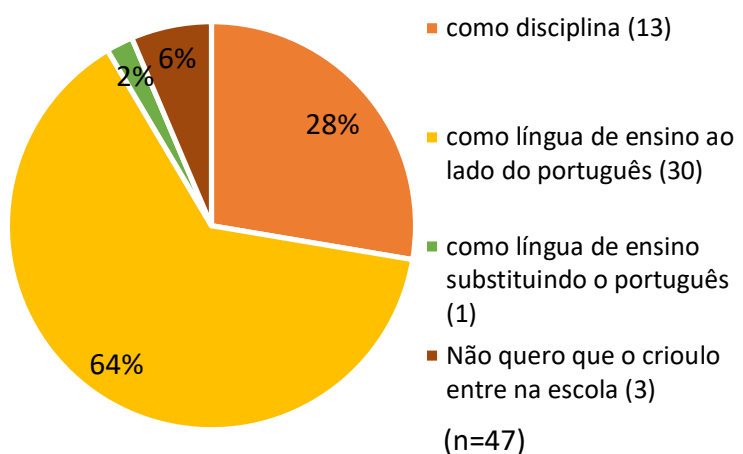

Figura 3 - UNESCO

19. Concorda com a seguinte declaração da UNESCO?

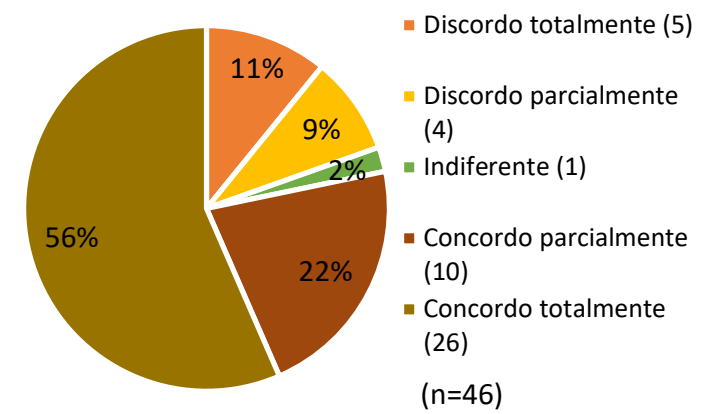

Fonte: o autor.

Apresentamos, no que segue, os argumentos principais em favor da introdução do crioulo na escola, levando em consideração as declarações tanto dos participantes do questionário, quanto os comentários dos leitores:

1. A valorização da própria L1.

2. A valorização do crioulo como verdadeira língua que tem regras e que pode ser ensinada como qualquer outra língua.

3. O domínio do crioulo promove a capacidade de distinguir sistematicamente o crioulo do português e ajuda na aprendizagem de línguas estrangeiras.

4. Os alunos acompanham melhor os cursos.

5. O uso do crioulo reduz a insegurança linguística na sala de aula.

6. A valorização de um bilinguismo (crioulo-português) equilibrado.

Mencionamos acima que as línguas crioulas ainda carregam o estigma de serem línguas inferiores e que têm menor prestígio em relação às línguas dos antigos colonizadores. As declarações dos participantes apontam para uma mudança dessa perspectiva a favor de uma maior valorização da língua crioula concedendo-Ihe um prestígio igual ao do português e de outras línguas como língua de pleno direito com regras. A introdução do crioulo na escola ajudaria nesse caminho:

(1) "O crioulo precisa ser valorizado no contexto escolar e formal e precisamos aprender e usar melhor a vertente escrita" (F41ST) ${ }^{17}$.

(2) "Porque há pessoas que pensam que o Crioulo é uma língua que não tem regra e que todos sabemos escrever e falar bem o crioulo, mas o que não sabem é que o crioulo não se escreve de qualquer forma e que assim como o português, inglês, francês... têm regra o crioulo também tem. Daí a necessidade de ser ensinada como disciplina" (F27STc).

\footnotetext{
${ }^{17}$ Cada participante tem uma sigla, que é composta por três elementos: sexo ( $M=$ masculino, $F=$ feminino), idade e ilha de residência ( $M=$ Maio, $S=S A L, S A=$ Santo Antão, $S T=$ Santiago, $S V=$ São Vivente, SN = São Nicolau). Caso os três elementos sejam iguais, acrescenta-se uma letra minúscula. Foram corrigidos os erros de digitação, de ortografia e de concordância, mantendo a ortografia original usada pelos informantes que segue a ortografia da variedade europeia da língua portuguesa.
} 
(3) "Porque acredito que devemos conhecer as regras da nossa língua materna" (F25ST).

Além disso, uma justificativa que parece ser muito simples e lógica, mas que não é em contextos diglóssicos, exprime-se no fato de que o crioulo é a primeira língua, na qual se sabe comunicar e expressar de melhor maneira:

(4) “Porque o crioulo é a língua que nasce connosco, é nela que pensamos, sonhamos, imaginamos, comunicamos enfim tudo o que fazemos é na nossa língua materna. E é nela que expressamos melhor" (F27STd).

(5) “Cabo-verdiano pensa no crioulo e faz as suas lógicas também em crioulo" (M42ST).

(6) "Não podemos continuar a fingir que a nossa língua materna não existe e mantê-la fora do sistema educativo" (A. J. CARDOSO em Notícias do Norte 2017).

Como consequência, a melhoria da competência oral e escrita na L1 resultaria na melhor capacidade de distinguir mais claramente entre o português e o crioulo:

(7) “Devemos ter em conta o estatuto e a função da língua cabo-verdiana e da língua portuguesa. A primeira trata-se da língua materna, mas não é a língua oficial dos cabo-verdianos. A segunda tem o estatuto da língua oficial e a função da língua segunda. Com o ensino de ambas as línguas acima referidas, isto ajuda tanto o aluno como os professores na análise contrastiva entre esses dois idiomas, o português e a língua cabo-verdiana, para descobrirem as semelhanças e as diferenças que existem entre elas, também para levar os alunos a evitar a transferência de ambas as línguas portuguesa e a caboverdiana (crioulo)" (F34SA).

Muitos informantes consideram vantajoso para os alunos a língua de instrução corresponder à $L 1$, o que tem um efeito positivo no desempenho da aprendizagem e que pode levar a melhores resultados de aprendizagem:

(8) “Com a introdução do crioulo em Cabo Verde ao lado do português os alunos compreenderão melhor os conteúdos leccionados pelos professores em todas as disciplinas do currículo em cada nível de ensino. Com essa medida os alunos ganhariam e o sistema de ensino sairia a ganhar com resultados positivos" (M44ST).

(9) “Porque a informação está na língua conhecida, não precisa ter um nível acadêmico elevado para compreender certas informações, se a pessoa é ensinada na língua materna" (F37ST).

Ao mesmo tempo, o uso da L1 incentivaria uma participação mais ativa dos alunos na sala de aula, que não seriam mais inibidos pela insegurança linguística:

(10) "Na sua língua materna a criança sente-se confiante, e sem medo de participar em aula, além de outras vantagens tais como conhecer os aspetos fonológicos e fonéticos da língua" (F38STa). 
(11) “Porque é a língua que a criança teve o contato com ela desde cedo. Às vezes, o aluno sabe o conteúdo, mas não sabe explicar em língua portuguesa por medo de errar" (F27STb).

No entanto, analisando as opiniões expressas, também fica claro que a maioria dos participantes não pretende banir o português do sistema escolar em favor do crioulo, como Duarte, que comenta que "[...] ter-se-á de compreender que a promoção do crioulo [...] nunca poderá fazer-se em detrimento do português" (DUARTE, 1998, p. 21). Os participantes manifestam-se, muito pelo contrário, a favor da coexistência sem conflitos das duas línguas:

(12) “O ensino do português como segunda língua exigiria um ensino, na primeira fase da aprendizagem das crianças, em crioulo. Depois, gradualmente, envolver-se-ia o português. Não pretendo que não se deve [sic] estudar o português em Cabo Verde. Isso seria absurdo" (João Rosa, investigador caboverdiano nos Estados Unidos, citado em RTC de 17/03/2011).

(13) “Portugês ku kriolu, tudu dos é di nos. Nu meste tudu dos. Es ka é nen nunka nu ka debe fazê-s torna inimigu, es debe ser prinsipal aliadu di kunpanheru"18 (M41SN).

(14) "Penso que as duas línguas podem conviver como línguas de ensino, o que seria uma mais valia, principalmente nos primeiros anos de ensino" (F39ST).

No lado dos oponentes, são os argumentos principais contra a introdução do crioulo na escola:

1. Há muita variação linguística, não existe um centro normativo do crioulo.

2. A imposição de um único padrão crioulo para a educação representa um perigo para a unidade nacional, em detrimento das diferentes variedades diatópicas.

3. O crioulo carece de estandardização.

4. O domínio do português dos cabo-verdianos já tem piorado nos últimos anos.

5. A integração do crioulo prejudica a manutenção e transmissão do patrimônio cultural e linguístico colonial.

6. O português e outras línguas internacionais têm maior valor econômico e garantem o desenvolvimento de Cabo Verde e a sua abertura ao mundo.

7. A integração do crioulo na escola seria muito cara.

8. Não há, ao nível mundial, muitos falantes do crioulo.

Um argumento frequente contra a introdução do crioulo nas escolas de Cabo Verde diz respeito à escolha de uma variedade crioula de referência. A existência de várias variedades diatópicas dificultaria a escolha da variedade a ser utilizada nas escolas:

(15) "Acho que o fato de haver vários tipos de crioulo é difícil introduzir na escola. Se houvesse um único crioulo acho que seria viável, mas não é o caso. Qual dos crioulos se introduziria? A de Praia, capital com certeza. Nem todos estão dispostos a falar o crioulo de Praia. Por tanto acho que cada um fala o seu

\footnotetext{
18 "Português e crioulo são nossos. Precisamos de ambos. Nunca devemos fazer deles inimigos, eles devem ser os primeiros aliados mútuos" (tradução nossa, ortografia da citação inalterada).
} 
crioulo no seu dia a dia e que o português continue sendo a língua oficial. Nos favorece mais" (F30SA).

(16) "Muito difícil colocá-lo na escola por causa das variantes da língua que existe de ilha para ilha. Até poderia escolher a opção como disciplina, mas viria uma questão logo de seguida. Qual dos crioulos?” (F33SV).

(17) "Bilingue? Como assim? Acho que mais certo seria multilíngue, sendo que são nove crioulos. Angustiante será um pobre menino de Santo Antão aprender no crioulo de Santiago. Me desculpe, mas todo o caboverdiano pode não saber falar, mas em português todos nós nos entendemos. Será que em crioulo também é assim? Eu sou de São Vicente e às vezes tenho muita dificuldade em entender pessoas do Fogo por exemplo" (comentário do leitor em NN).

(18) "[...] eu que só sei falar sampadjudo" ${ }^{19}$. Tenho muita dificuldade em entender o badio. Será que vou ter que aprender badio e depois sampadjudo? Essa não" (comentário do leitor em EDI).

(19) “Pois os caboverdianos não têm todos que falar a língua de Santiago, que é o verdadeiro programa encapotado. Que aprofundem o ensino e a prática da língua portuguesa e de outras. A língua portuguesa alimentou e conviveu 5 séculos os crioulos de Cabo Verde. A mão dos fundamentalistas de Santiago e de Esquerdistas é por demais evidente neste projeto" (comentário do leitor em EDI).

Consequentemente, a escolha de uma variedade seria um perigo para a unidade nacional. Encontramos este argumento apenas nos comentários do leitor e nos jornais em que o debate é mais político e polêmico:

(20) 'Uma eventual imposição de 'um crioulo', provocaria, obviamente, divisões e inevitáveis tensões sociais, a nível nacional, como já se começa a sentir" (artigo de opinião em AN).

(21) “Um aviso aos fundamentalistas de Santiago: Se o badio for imposto em Cabo Verde a Praia pode declarar a sua independência. Deve-se apelar a desobediência cívica em Cabo Verde" (comentário do leitor em EDI).

(22) "O que é que Cabo Verde ganha com o crioulo mais nacionalismo estreito de uma certa etnia? Agora fechar-se no umbigo é mau conselheiro. Se esta minoria não está contente com o bilinguismo em Cabo Verde que é a única via razoável e sustentável então que o diga e que apresente soluções. Essa minoria pode optar por exemplo pela independência e criar um estado separado só para o seu crioulo" (comentário do leitor em EDI).

A falta da normatização do crioulo é outro argumento contra a introdução do crioulo no sistema educativo cabo-verdiano:

(23) "Considerando o estágio de desenvolvimento da descrição do cabo-verdiano (crioulo de CV), assim como a inexistência de uma norma escrita, ou, ainda, de estudos comparativos, no campo metodológico e didático, inviabilizam, a meu ver, a sua introdução imediata como língua de ensino, ao lado do português" (F53SV).

(24) "Ainda não há regras que justifique [sic] um suporte escolar correto. Não sei como será ministrado, mas será feito de maneira mais ou menos arbitrária" (artigo de opinião em AN).

\footnotetext{
${ }^{19}$ A designação 'badio' refere-se aos habitantes da ilha de Santiago e também à variedade do crioulo falada nessa ilha, ao passo que 'sampadjudo' se refere aos habitantes das outras ilhas e às suas variedades do crioulo.
} 
Algumas pessoas temem que a introdução do crioulo possa pôr em perigo o desenvolvimento do país, pois o crioulo, na orquestra internacional de línguas, teria um valor econômico inferior ao do português ou de outras línguas internacionais que garantiriam a abertura e a conexão do país e do cidadão cabo-verdiano ao mundo:

(25) “Mas também é importante que se crie condições para o ensino/aprendizagem das outras línguas, uma vez que é fundamental que o indivíduo se abre [sic] ao mundo" (F25ST).

(26) "Cada língua abre-nos para um novo universo de ideias e valores, que nos cultiva mais e os reflexos serão sempre positivos e nos ajudará a fazer uma melhor integração no espaço económico e político do continente africano [...] A prioridade hoje, a nível de línguas, é: mais português, muito mais inglês e francês, pois, com a nossa língua materna nunca teremos problemas, ela faz parte do nosso DNA" (artigo de opinião em AN).

(27) "Não seria melhor ensinar nas escolas, além do português, o inglês e o francês, já que somos buscadores de vida por esse mundo fora. Se um cabo-verdiano chegar mesmo em Lisboa, e só sabe falar crioulo, não é capaz de ficar sem pedir uma refeição num restaurante?" (comentário do leitor em NN).

Ademais, segundo alguns, as proficiências na língua portuguesa têm vindo a diminuir nos últimos anos, o que seria reforçado com a introdução do crioulo nas escolas:

(28) “Um dos grandes problemas dos nossos estudantes que vêm para a universidade em Portugal é não dominarem a língua para se expressarem nela em condições e escreverem, o que não acontecia antigamente. Levando-se avante a teimosia do MED, os licenciados em Cabo Verde terão de contratar intérpretes e tradutores portugueses para entenderem e dialogar com colegas portugueses" (comentário do leitor em EDI).

(29) "Explique-me também o que é que mudou em Cabo Verde que os alunos agora têm enormes problemas de expressão na língua portuguesa? Certamente que alguma coisa vai mal" (comentário do leitor em EDI).

As preocupações também se referem aos recursos humanos e desafios financeiros necessários que o país enfrentaria desenvolvendo material didático adequado:

(30) “A introdução do crioulo implica construção de novos manuais escolares ou tradução de livros, o que ficaria muito caro para nosso país, país este, com poucos recursos" (F33SV).

(31) "Para uma eventual aposta no crioulo, precisar-se-ia de muito tempo e dinheiro não só para pagamentos de equipas de consultoria na matéria, como também na planificação e concepção de vários instrumentos necessários ao seu ensino e à sua aprendizagem. Isto sem falar de um trabalho apurado para a sua introdução nas NTIC. Daí que, se se fizer uma análise prévia e cuidada do custobenefício, o resultado de tudo isso reduziria em nada" (artigo de opinião em AN).

(32) “Este projeto não tem viabilidade económica. Vai acarretar enormes custos e prejuízos para Cabo Verde" (comentário do leitor em EDI). 
Aqui retomamos a relação entre a L1 (crioulo) e a língua de ensino (português) no contexto escolar em Cabo Verde. O português foi a única língua de ensino para 46 participantes (96\%), para mais uma pessoa foram o crioulo e o português as línguas de ensino. Para uma pessoa, foi apenas o crioulo, embora seja possível questionar a veracidade dessa informação, tendo em conta que o ensino totalmente em crioulo não existia naquela época. Quase metade dos entrevistados (47\%) discorda da afirmação de que a língua teria causado dificuldades durante sua escolaridade, outros $21 \%$ concordam apenas parcialmente com a afirmação (figura 4). $24 \%$ dos entrevistados concordam com a afirmação parcialmente, $6 \%$ totalmente e uma pessoa prefere não tomar uma posição concreta.

Figura 4 - Dificuldades na escola

18. Tenho / Tinha dificuldades ou problemas na escola por causa da língua.
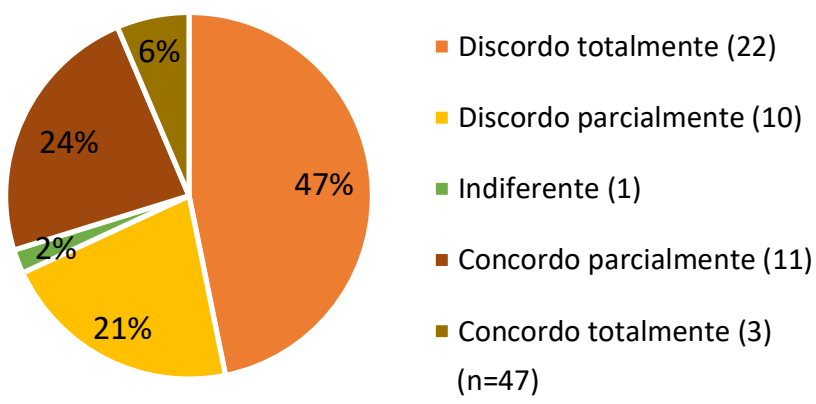

Fonte: o autor.

É interessante ver os diferentes comportamentos linguísticos dos informantes conforme a situação de conversação na escola (tabela 2). Quando falavam com o professor, usavam principalmente o português (cerca de $80 \%$ ). Com seus colegas, eles falavam principalmente crioulo dentro da sala de aula, mas também usavam português. No entanto, assim que saíam da sala de aula para o intervalo, trocando um ambiente mais formal por um ambiente mais informal, preferiam usar muito mais o crioulo em vez do português.

Tabela 2 - Português e crioulo no contexto escolar

\begin{tabular}{lcccc} 
& Português & Crioulo & Ambas & Outra(s) \\
\hline $\begin{array}{l}\text { 13. Em que língua estão / estavam } \\
\text { escritos os manuais escolares? }\end{array}$ & $97,92 \%$ & - & $2,08 \%$ & - \\
$\begin{array}{l}\text { 14. Em que língua(s) fala / falava com o } \\
\text { professor? }\end{array}$ & $79,17 \%$ & $4,17 \%$ & $16,67 \%$ & - \\
$\begin{array}{l}\text { 15. Em que língua(s) fala / falava com os } \\
\text { seus colegas durante as aulas? }\end{array}$ & $16,67 \%$ & $56,25 \%$ & $27,08 \%$ & - \\
$\begin{array}{l}\text { 16. Em que língua(s) fala / falava com os } \\
\text { seus colegas durante o recreio? }\end{array}$ & $4,17 \%$ & $87,50 \%$ & $8,33 \%$ & - \\
\end{tabular}

Fonte: o autor. 
Analisando as respostas dos informantes em relação à existência, ou não, de dificuldades na escola por causa da língua, fica claro que as experiências na escola relacionadas ao português e ao crioulo dependem de vários fatores. Por um lado, um fator encontra-se no nível do indivíduo e em que maneira ele é capaz de lidar com as exigências escolares em geral e com os desafios linguísticos resultantes do fato de o português não ser a L1. Por outro lado, talvez o aspecto mais importante e decisivo é a intensidade do contato com o português dentro da família e na vida cotidiana antes de a criança entrar na escola. Esse contato pode ser representado em uma escala que vai de 'nenhum contato com o português antes de entrar na escola' a 'educação bilíngue em casa (crioulo e português)'. Essa variável pode também depender se a criança cresceu em meio rural com nenhum ou pouco contato com o português ou em meio urbano com contato mais frequente ao português.

Vejamos algumas justificativas dos informantes que discordam totalmente (33-35) ou parcialmente (36-38) de ter tido dificuldade na escola por causa da língua:

(33) "A língua nunca constituiu dificuldades para mim, pois sempre tive bons desempenho na língua de ensino, que é o português" (M48ST).

(34) "Discordo, porque mesmo sendo cabo-verdiana, o português nunca atrapalhou na minha aprendizagem" (F27d).

(35) "Nos primeiros anos da escola tive que aprender o português, mas foi um processo natural e até gratificante. Tive a sorte de ter boas professoras, bem preparadas academicamente, profissionalmente e pessoalmente enquanto pessoas de grandes qualidades humanas" (F61ST).

(36) "Porque às vezes nem os próprios professores sabem falar correctamente e isto cria uma confusão na mente" (F26ST).

(37) "Devido às interferências tive algumas dificuldades" (F34ST).

(38) "Houve momentos, no início da aprendizagem da língua portuguesa, às vezes não me sentia muito à vontade porque, quando se cometia algum erro, os colegas gozavam uns com os outros" (F41ST).

Seguem as explicações dos participantes que concordam parcialmente (39-41) ou totalmente (42 e 43) que tinham dificuldades na escola por causa da língua:

(39) "Só mais tarde, na idade adulta, ganhei consciência que tinha dificuldades em determinadas matérias, por causa da formulação linguística e não pelo assunto em si. A filosofia, por exemplo" (M45ST).

(40) "Porque às vezes não queria falar português, porque inseria palavras do crioulo para português e sentia vergonha de falar" (F21STa).

(41) "Tinha dificuldades, porque a aprendizagem de qualquer língua exige prática, educação e reforço pessoal que foram superados com tempo" (F38STb).

(42) "Porque na casa e toda a infância antes de ir à escola fala-se a língua materna, chegando na escola uma outra língua muitas vezes depara-se com grandes dificuldades" (F37ST).

(43) “Não dominava muito bem a língua" (F27a).

Pode-se observar que, para alguns informantes, o contato com o português antes de entrar na escola era menos desenvolvido em comparação ao dos seus colegas, de modo que o ensino em português no início da escola foi um obstáculo que, embora não insuperável, 
exigia um investimento adicional de tempo e esforços intelectuais. Além disso, alguns informantes (39 e 41) ainda não dominavam o português de forma adequada para seguir sem problemas as aulas ou foram expostos a comentários jocosos de seus colegas. Essas experiências negativas associadas ao emprego de uma língua podem ser um obstáculo no processo de aprendizagem de uma língua. As desigualdades entre os alunos de Cabo Verde existem antes mesmo de entrarem na escola. Um sistema escolar conseguiria nivelar as desigualdades se lidasse adequadamente com os diferentes perfis linguísticos de todos os alunos com base em uma língua à qual uma grande maioria tenha mais ou menos o mesmo acesso, isto é, o crioulo. As declarações (40), (42) e (43) aludem a um fenômeno presente em contextos linguísticos complexos, a saber, à 'insegurança linguística' que ocorre "quando os falantes consideram sua maneira de falar não muito gratificante e têm em mente outro modelo mais prestigiado, mas não o praticam" ${ }^{20}$ (CALVET, 1993, p. 50, tradução nossa). Sendo assim, surge a questão se seria desejável, hoje em dia, expor os alunos a desvantagens evitáveis, caso o sistema educativo pudesse considerar a realidade linguística no país.

\section{Escrever em kabuverdianu: conhecimento do alfabeto ALUPEC}

Para ser capaz de escrever em uma determinada língua e usá-la como língua de ensino, é necessário um alfabeto. Vários séculos transcorreram até que os alfabetos das línguas românicas fossem desenvolvidos como os conhecemos hoje. A história da escrita do kabuverdianu é mais curta e, de forma semelhante, caracterizada também por propostas diferentes, por heterogeneidade, por aceitação, por rejeição e por resistência dos falantes. Esse comportamento dos falantes não é incomum e está bem conhecido na história da escrita de outras línguas. Basta pensar nos debates que qualquer reforma da ortografia (seja nas línguas francesa, portuguesa ou alemã) provocou entre os falantes. Não obstante, não se trata, neste artigo, da questão da trajetória da ortografia do kabuverdianu descrita por outros autores (cf. p. ex. SILVA, 1995; VEIGA, 2002, p. 48-49; BAPTISTA; BRITO; BANGURA, 2010, p. 285-295). Em 1998, o Alfabeto Unificado para a Escrita do Cabo-verdiano (ALUPEC) foi aprovado por Decreto-Lei no 67/98 como alfabeto cabo-verdiano a título experimental durante quatro anos, tornando-se o alfabeto oficial para a escrita do kabuverdianu em 2009 (cf. Boletim Oficial, 2009, I série, n.o 11). Com este alfabeto, tencionou-se realizar a ideia de que um signo representa um som e que todas as variedades de crioulo podem ser escritas à base dele (BAPTISTA; BRITO; BANGURA, 2010, p. 289).

No questionário, perguntava-se se o ALUPEC era conhecido, se o utilizava e quais foram os argumentos a favor ou contra a sua utilização. A figura 5 mostra que $82 \%$ dos entrevistados conhecem o ALUPEC ${ }^{21}$. Assumiríamos que o nível de familiaridade com o

\footnotetext{
${ }^{20}$ Original: "Iorsque les locuteurs considèrent leur façon de parler comme peu valorisante et ont en tête un autre modèle, plus prestigieux, mais qu'ils ne pratiquent pas".

${ }^{21}$ Uma pessoa respondeu que não conhecia o ALUPEC, mas à pergunta seguinte, perguntando se está usando o ALUPEC ou não, explica "utilizo o ALUPEC por opção própria” (M37ST). Decidimos, portanto, tomar sua resposta como um voto a favor do conhecimento do ALUPEC.
} 
ALUPEC é, de maneira geral, muito menor entre a população cabo-verdiana do que o resultado deste estudo mostra. Não há uma política linguística a longo prazo ativa, informando o povo cabo-verdiano, que assim não tem consciência da existência do ALUPEC. Isso também impede a sua aceitação: "As questões locais tendem a dificultar a aceitação e o uso de ortografias, mas parece que a falta de conscientização do público constitui um importante fator de contribuição"22 (MIGGE; LÉGLISE; BARTENS, 2010, p. 9, tradução nossa).

\section{Figura 5 - Nível de familiaridade do ALUPEC}

20. Conhece o ALUPEC?

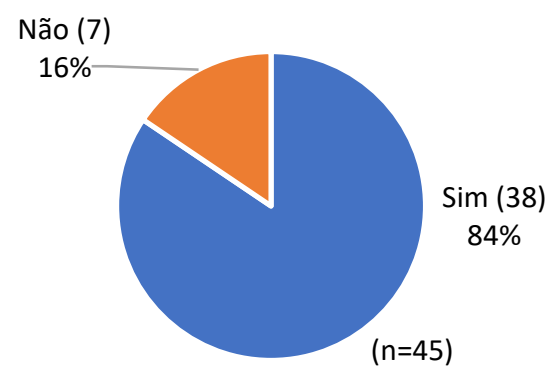

Fonte: o autor.

O elevado nível de consciência do ALUPEC entre os informantes deve-se certamente ao fato de muitos informantes trabalharem no setor educacional enquanto professores e docentes ou estarem estudando Estudos Cabo-Verdianos e Portugueses, áreas nas quais a consciência das questões linguísticas em uma sociedade deveria tender a ser mais acentuada. Após esta pergunta, os informantes devem explicar se usam ou não o alfabeto justificando a resposta. Apenas três informantes que conhecem o ALUPEC não o utilizam. As respostas mostram que alguns informantes que estão usando o ALUPEC ativamente também são críticos quanto ao alfabeto. Vejamos primeiro algumas das razões apresentadas pelos utentes do ALUPEC:

(44) “É a forma mais eficaz e próxima daquilo de se fala. É a única forma conhecida de aproximar todas as variantes do crioulo" (M38M).

(45) "Porque melhora a nossa escrita e diferencia o crioulo do português. Mas sobretudo porque é a regra da nossa língua" (M26ST).

(46) "Porque a escrita é uma convenção social. Devemos seguir um padrão para não haver confusão" (F38STc).

(47) "Sim, utilizo o ALUPEC, porque ele possui regras claras, simples e eficaz etc. que me ajuda a escrever com mais autoridade na minha língua materna" (M27ST).

(48) “Porque é uma proposta boa, a precisar de ajustes no entanto" (M45ST).

Os comentários dos usuários ativos mostram a necessidade de ter um alfabeto para poder escrever a sua própria L1. O alfabeto seria "eficaz" e "simples" com "regras claras" (44

\footnotetext{
${ }^{22}$ Original: "Local issues tend to hamper the acceptance and use of orthographies, but it seems that the lack of public awareness constitutes an important contributing factor".
} 
e 47) e poderia ser aplicado para harmonizar a escrita de todas as variedades (44). O ALUPEC levaria também a uma distinção mais clara entre o crioulo e o português (45), evitando a "confusão" (46), provavelmente entre diferentes sistemas de escrita.

A porcentagem daqueles que utilizam o ALUPEC tendo uma atitude positiva em relação a ele supera a porcentagem daqueles que o rejeitam ou se mostram comedidos em relação ao seu uso. O ALUPEC não preencheria todos os requisitos para um alfabeto e teria pontos fracos na sua implementação (49 e 50). Por outro lado, não faria sentido (51) e forçaria a "ideia de africanização" (52), sem explicar com mais detalhes o que se entende por isso:

(49) "Embora o utilize parcialmente porque não me parece responder, de forma eficaz e corrente, a todas as situações de escrita com as quais sou confrontada" (F53SV).

(50) “Não concordo com alguns aspetos da grafia" (F38STa).

(51) “Não faz sentido para mim" (F43S).

(52) "Não fixo as regras e tenho alguma resistência quanto à imposição de uma certa ideia de africanização forçada" (M67ST).

Finalmente, consideramos a avaliação do status e do prestígio do português e do kabuverdianu na perspectiva dos falantes.

\section{Crioulo e português: status e prestígio}

Como vimos, o kabuverdianu e o português estão em uma constelação de diglossia, em que o português é atualmente a língua à qual é atribuído o maior prestígio. Referindo-se aos trabalhos da sociolinguística catalã, Kremnitz (2002) distingue entre o status e o prestígio de uma língua. O status é o status legal de uma língua que se reflete na legislação. O prestígio é o prestígio social ou a aceitação social de uma língua. Outra distinção é feita entre o prestígio interno, isto é, o prestígio de que o idioma desfruta por seus falantes, e o prestígio externo, isto é, o prestígio que pessoas não pertencentes ao grupo em questão atribuem ao idioma (KREMNITZ, 2002, p. 122-123):

Neste contexto, é importante notar que o prestígio de que as línguas numa sociedade desfrutam (ou não desfrutam) muitas vezes orienta a política linguística, indiferentemente se se trata da definição do status das línguas nos Estados, do ensino de línguas estrangeiras nas escolas, da oficialidade das línguas nas organizações internacionais, por exemplo, ou de outras medidas de política linguística (KREMNITZ, 2002, p. 125, tradução nossa). ${ }^{23}$

Kremnitz (2002, p. 125) deixa claro que o prestígio raramente pode ser racionalmente

\footnotetext{
${ }^{23}$ Original: "Wichtig ist in diesem Zusammenhang, dass das Prestige, das Sprachen in einer Gesellschaft genießen (oder nicht genießen), häufig handlungsleitend für die Sprachenpolitik wird, gleichgültig, ob es sich um die Festlegung des Status von Sprachen in Staaten, den schulischen Fremdsprachenunterricht oder die Offizialität von Sprachen etwa in internationalen Organisationen oder um andere sprachenpolitische Maßnahmen handelt“ (grifo no original).
} 
justificado. Não são tanto os critérios linguísticos que desempenham um papel importante, mas sim, fatores externos ao idioma. Por exemplo, o sucesso econômico de uma região ou país também se reflete no prestígio dos idiomas em questão, enquanto as línguas de inimigos são menos estimadas.

Assim como as condições sociais podem ser afetadas por mudanças, o prestígio de uma língua pode mudar com o tempo devido, por exemplo, a mudanças sociais, políticas ou econômicas. Nem o prestígio, nem o status são valores estáveis. Kremnitz (2002, p. 126-127) introduz uma outra variável, o valor comunicativo de uma língua, que também é um valor sujeito a tempo e espaço, razão pela qual nenhuma língua tem sempre a mesma importância. Uma língua pode ter um alto valor comunicativo em um determinado momento e lugar, enquanto pode ser inútil em outro contexto comunicativo. Em Cabo Verde, o kabuverdianu tem um alto valor comunicativo na vida cotidiana dos cabo-verdianos. Nos domínios linguísticos mais formais, o valor comunicativo do kabuverdianu é menor, já que o valor comunicativo atribuído ao português é maior. Fora das fronteiras nacionais, o valor comunicativo do kabuverdianu é ainda menor, pelo menos nas regiões do mundo onde não existe uma diáspora cabo-verdiana em que o uso do kabuverdianu seja possível e útil. Contudo, o domínio de mais de uma língua é uma vantagem valiosa: "O domínio de apenas um idioma adicional proporciona ao falante um capital adicional nesse sentido"24 (KREMNITZ, 2002, p. 124; cf. também BOURDIEU; PASSERON, 1970, p. 144).

Veem-se na tabela 3 os resultados às perguntas 24 e 25 em que os participantes deviam marcar com uma cruz se o português / o crioulo é uma língua ou um dialeto, se tem gramática, se é do passado, se é adequado para todas as pessoas, para ser usado em casa e para ser usado na escola. Deve-se notar que não foi dada uma definição de 'língua', 'dialeto' ou 'gramática' aos participantes, o que torna um pouco especulativa a interpretação dos dados. Além disso, tornam-se evidentes as discrepâncias e inconsistências que podem ocorrer nas respostas de um participante no decorrer de um questionário, deixando, às vezes, os autores do questionário desorientados na avaliação dos resultados.

Tabela 3 - Crioulo e português

\begin{tabular}{|c|c|c|c|c|}
\hline & \multicolumn{2}{|c|}{ 24. O que acha do crioulo? } & \multicolumn{2}{|c|}{ 25. O que acha do português? } \\
\hline & Sim & Não & Sim & Não \\
\hline É uma língua. & $92,68 \%$ & $7,14 \%$ & $100,00 \%$ & - \\
\hline É um dialeto. & $21,43 \%$ & $78,57 \%$ & $11,90 \%$ & $88,10 \%$ \\
\hline Tem gramática. & $85,71 \%$ & $14,29 \%$ & $100,00 \%$ & - \\
\hline É do passado. & $19,05 \%$ & $80,95 \%$ & $21,43 \%$ & $78,57 \%$ \\
\hline É adequado para todas as pessoas. & $88,10 \%$ & $11,90 \%$ & $88,10 \%$ & $11,90 \%$ \\
\hline É adequado para ser usado em casa. & $100,00 \%$ & - & $85,71 \%$ & $14,29 \%$ \\
\hline É adequado para ser usado na escola. & $83,33 \%$ & $\begin{array}{c}16,67 \% \\
(n=42)\end{array}$ & $100,00 \%$ & $\begin{array}{c}- \\
(n=42)\end{array}$ \\
\hline
\end{tabular}

Fonte: o autor.

\footnotetext{
${ }^{24}$ Original: "Die Beherrschung nur einer einzigen zusätzlichen Sprache versieht den jeweiligen Sprecher in diesem Sinne mit zusätzlichem Kapital".
} 
Parece, no entanto, que os informantes têm uma certa noção não especificada dos conceitos, eventualmente transmitidos pelas instituições educativas que frequentaram. Assumimos que os participantes associam 'língua' a uma forma linguística que pode ser utilizada em todos os domínios linguísticos, tais como inglês, francês, espanhol etc. Também assumimos que os participantes associam 'dialeto' a uma forma linguística/meio comunicativo que não tem todos os requisitos para ser usada em todos os domínios linguísticos em comparação à 'língua'.

Para todos os participantes não há dúvida de que o português é uma língua. De um ponto de vista linguístico, é certamente surpreendente que $11,90 \%$ classifiquem o português também como um dialeto na seguinte questão, o que não pode ser explicado mais detalhadamente com base nos nossos dados. O crioulo é uma língua para $92,68 \%$ dos participantes. Esse é um número alto, mas também mostra que para alguns participantes falta "algo" ao crioulo para classificá-lo como uma língua. A avaliação é ainda mais notável quando se olha mais de perto os perfis daqueles que consideram o crioulo como um dialeto. São uma psicóloga clínica (F30SA), uma docente universitária (F33SV) e um professor de língua inglesa (M44ST). Os três informantes têm o kabuverdianu como L1, usam-no na vida cotidiana e cada um deles afirma que fala e entende crioulo 'muito bem'. Enquanto F30ST e F33SV afirmam que falam e entendem português 'muito bem', M44ST classifica suas competências em falar português e na compreensão oral como 'bom' e 'muito bom'. Apesar desses perfis linguísticos serem ligeiramente a favor do kabuverdianu, eles classificam a sua própria L1 não como uma língua, mas como um dialeto. É possível que esses falantes atribuam um menor prestígio interno ao crioulo do que ao português. Contudo, também é concebível que eles não tenham avaliado o kabuverdianu em geral, mas a sua própria variedade do crioulo (crioulo de Santo Antão, crioulo de São Vicente, crioulo de Santiago) que eles, talvez, entendam como um 'dialeto' do kabuverdianu. Não obstante, para sair da área de especulação e para interpretar os resultados de forma mais válida, teria sido necessário, sem dúvida, perguntar posteriormente aos participantes por que razão tinham assinalado 'dialeto' ou 'língua'.

Os resultados à resposta se o português e o crioulo dispõem de uma gramática, ou seja, de um sistema de regras estrutural, podem ser avaliados como mais um indício de que os falantes atribuem um maior prestígio ao português do que ao crioulo. Todos os participantes acreditam que o português tem uma gramática. O crioulo tem uma gramática para apenas $85,71 \%$ embora o L1 de todos os opositores - incluindo F30SA e F33SV - seja exclusivamente crioulo. Certamente, essa avaliação está relacionada a uma variedade padrão ainda ausente, pois a padronização do kabuverdianu está em processo.

\section{Considerações finais}

Pode-se resumir que a maioria dos participantes do questionário é a favor da introdução do kabuverdianu nas escolas. Nas colunas de comentários dos artigos online, no entanto, predomina uma atitude reservada e até negativa em relação à introdução do kabuverdianu nas escolas. Os resultados do presente estudo confirmam bastante os 
resultados de estudos semelhantes anteriores na década de 1990 e no início do século XXI feito por Baptista e Sanches: "é seguro assumir que, muito provavelmente, uma parte significativa da população cabo-verdiana é a favor de melhorar o status da língua e de aumentar a sua visibilidade em esferas onde o português é tradicionalmente dominante"25 (BAPTISTA; BRITO; BANGURA, 2010, p. 281-284, tradução nossa). Contudo, devido ao pequeno número de participantes, os estudos não podem ser considerados representativos da opinião de toda a população cabo-verdiana.

O fato de que decisões e desenvolvimentos relativos à linguagem no meio de uma sociedade podem sempre assumir uma dimensão política fica evidente no exemplo de um grupo de orientação política em uma plataforma de mídia social com pouco mais de 1000 membros. Este grupo defende a criação de uma República de Cabo Verde do Norte para se desvencilhar do domínio político e cultural da ilha de Santiago com sua capital Praia. O grupo tem a rejeição do ALUPEC expressis verbis no seu nome "Cabo Verde do Norte Independente e sem Alupek". Aparentemente, o ALUPEC é visto como um instrumento de Santiago para dominar linguisticamente as outras ilhas, em detrimento das outras variedades insulares. A preferência por uma variedade certamente não foi pretendida pelos autores do ALUPEC. Estas opiniões opostas, mesmo que em pequena escala, mostram que é necessário um amplo consenso social. No entanto, para alcançar um amplo consenso social, é necessário fornecer à população informações completas para que ela, em um processo democrático, possa ouvir argumentos e contra-argumentos com base nos quais possa formar uma opinião, pois, afinal, são sua primeira língua e seu alfabeto que estão em jogo. Qualquer sistema de escrita, por mais bem pensado que seja pelos especialistas e linguistas, falhará na sua implementação se não houver apoio majoritário da população. A melhoria do sistema escolar também depende da decisão da liderança política que deve levar em conta a situação bilíngue em Cabo Verde: "As políticas linguísticas que visam e implementam soluções monolíngues utilizando apenas uma língua oficial, que também seria a utilizada em todos os ciclos ou pelo menos nos primários pós-infantis de educação formal, não podem e não funcionarão na África" ${ }^{26}$ (WOLFF, 2016, p. 265, tradução nossa).

É de se esperar que uma avaliação feita há dez anos sobre a situação da política linguística em Cabo Verde não permaneça válida por mais dez anos: “O fato, porém, é que até agora não foram tomadas medidas, em termos de política e práticas linguísticas, para abrir concretamente a educação à língua cabo-verdiana"27 (BAPTISTA; BRITO; BANGURA, 2010, p. 274, tradução nossa). Se os resultados dos estudos e as experiências dos falantes forem levados a sério, kabuverdianu deve ser permanentemente integrado no sistema escolar cabo-

\footnotetext{
${ }^{25}$ Original: "it is safe to assume that in all likelihood, a significant portion of the Cape Verdean population is in favor of enhancing the status of the language and of increasing its visibility in spheres where Portuguese is traditionally dominant".

${ }^{26}$ Original: "The language policies that target and implement monolingual solutions using just one official language, which would also be the one used in all or at least the post-lower primary cycles of formal education, cannot and will not work in Africa".

${ }^{27}$ Original: "The fact remains, however, that no steps have been taken so far, in terms of language policy and practices, to concretely open up education to the Cape Verdean language".
} 
verdiano sem pôr em causa a importância da língua portuguesa. Esse passo, no entanto, também requer mudanças na política linguística, que deve promover e realizar a oficialização do kabuverdianu.

\section{Referências}

BAPTISTA, M.; BRITO, I.; BANGURA, S. Cape Verdean in education: a linguistic and human right. In: MIGGE, B.; LÉGLISE, I.; BARTENS, A. (Org.). Creoles in Education: an appraisal of current programs and projects. Amsterdam; Philadelphia: Benjamins, 2010. p. 273-296. https://doi.org/10.1075/cll.36.11bap

BECKERT, R.; SCHRÖDER, N. L'opinion publique face au créole à l'école: une étude comparative à la Réunion et au Cabo Verde. Proceedings of the 16th colloquium of the Comité International des Études Créoles, Seychelles 2018. No prelo.

BOURDIEU, P.; PASSERON, J.-C. La reproduction: éléments pour une théorie du système d'enseignement. Paris: Minuit, 1970.

CALVET, L.-J. La sociolinguistique. Paris: Presse Universitaires de France, 1993.

CARDOSO, A. J. Notícias do Norte. Não podemos continuar a fingir que a nossa língua materna não existe e a mantê-la fora do sistema educativo. 23/02/2017. Disponível em: https://noticiasdonorte.publ.cv/56300/ana-cardoso-nao-podemos-continuar-fingir-nossalingua-materna-nao-existe-mante-la-do-sistema-educativo. Acesso em: 10 maio 2020.

DUARTE, D. A. Bilinguismo ou diglossia?: as relações de força entre o crioulo e o português na sociedade cabo-verdiana. Praia: Spleen, 1998.

Expresso das llhas. Hoje, neste dia de 2030. 24/05/2014. Disponível em: https://expressodasilhas.cv/opiniao/2014/05/24/hoje-neste-dia-de-2030/42150. Acesso em: 10 maio 2020.

FERGUSON, C. A. Diglossia. Word, v. 15, p. 325-340, 1959.

https://doi.org/10.1080/00437956.1959.11659702

FISHMAN, J. A. Bilingualism with and Without Diglossia; Diglossia With and Without Bilingualism. Journal of Social Issues, v. 23, n. 2, 29-38, 1967. https://doi.org/10.1111/j.15404560.1967.tb00573.x

HERRERAS, J. C. (Org.). Politiques linguistiques et langues autochtones d'enseignement dans I'Europe des vingt-sept. Valenciennes: Presses Universitaires, 2014.

KREMNITZ, G. Sprachenpolitische Entscheidungen zwischen Prestige und kommunikativer Bedeutung: Hintergründe und mögliche Folgen. In: AMBROSCH-BARUA, T., KROPP, A.; MÜLLER-LANCÉ, J. (Org.): Mehrsprachigkeit und Ökonomie. Open Publishing LMU, München: Universitätsbibliothek der Ludwig-Maximilians-Universität. 2017. p. 17-27.

KREMNITZ, G. Zu Status, Prestige und kommunikativem Wert von Sprachen. Quo vadis, Romania?, n. 20, p. 122-128, 2002.

LOPES, F. J. V. Multilinguismo como factor de integração na sub região. A Nação, 27/06/2015. Disponível em: https://anacao.cv/2015/06/27/multilinguismo-como-factor-de-integracaona-sub-regiao. Acesso em: 10 maio 2020. 
MIGGE, B.; LÉGLISE, I.; BARTENS, A. Creoles in Education: a discussion of pertinent issues. In: MIGGE, B.; LÉGLISE, I.; BARTENS, A. (Org.). Creoles in Education: an appraisal of current programs and projects. Amsterdam; Philadelphia: Benjamins, 2010. p. 1-30. https://doi.org/10.1075/cll.36.01mig

ROSA, A. C. B. S. Ensino bilíngue em Cabo Verde: desafios e práticas educativas. Trabalho de Conclusão de Curso, Universidade da Integração Internacional da Lusofonia Afro-Brasileira, 2017. Disponível em: http://repositorio.unilab.edu.br:8080/jspui/handle/123456789/602. Acesso em: 10 maio 2020.

ROUEN, A. A propósito da tentativa de imposição de "um crioulo" aos cabo-verdianos. A Nação, 12/02/2016. Disponível em: https://anacao.cv/2016/02/12/a-proposito-da-tentativade-imposicao-de-um-crioulo-aos-cabo-verdianos. Acesso em: 10 maio 2020.

SILVA, J. V. da. A estandardização da escrita do crioulo caboverdiano. Papia, v. 4, n. 1, p. 5661, 1995.

SINNER, C. Zur Terminologie in der Sprachkontaktforschung: Bilinguismus und Diglossie, Interferenz und Integration sowie tertiärer Dialekt. In: HAßLER, G. (Org.). Sprachkontakt und Sprachvergleich, Münster: Nodus, 2001. p. 125-152.

SWOLKIEN, D. Factores sociolinguísticos no povoamento da ilha de São Vicente de Cabo Verde. In: FERNÁNDEZ, M.; FERNÁNDEZ-FERREIRO, M.; VÁZQUEZ VEIGA, N. (Org.). Los criollos de base ibérica: ACBLPE 2003, Madrid; Frankfurt am Main: Iberoamericana; Vervuert, 2004. p. 171184. https://doi.org/10.31819/9783865278555-014

UNESCO. Journée de la langue maternelle: I'UNESCO plaide pour la diversité linguistique, 2017. Disponível em: https://news.un.org/fr/story/2017/02/352662-journee-de-la-languematernelle-lunesco-plaide-pour-la-diversite-linguistique. Acesso em: 10 maio 2020.

UNESCO. Records of the General Conference: 30th Session Paris, 26 October to 17 November 1999. Vol. 1: Resolutions. Paris: UNESCO, 2000.

Disponível em: https://unesdoc.unesco.org/ark:/48223/pf0000118514. nameddest=16. Acesso em: 10 maio 2020.

VEIGA, M. O caboverdiano em 45 lições: Estudo sociolinguístico e gramatical, Lisboa: INIC, 2002.

WOLFF, E. Language and development in Africa: perceptions, ideologies and challenges, Cambridge: University Press, 2016. https://doi.org/10.1017/CBO9781316105023

WOLFF, E. Language Politics and Planning in Africa. In: ALIDOU, H.; BROCK-UTNE, B.; DIALLO, Y. S.; HEUGH, K.; WOLFF, E. (Org.). Optimizing Learning and Education in Africa - the Language Factor: a Stock-taking Research on Mother Tongue and Bilingual Education in Sub-Saharan Africa. ADEA; UNESCO Institute for Education; Deutsche Gesellschaft für Technische Zusammenarbeit. Working Document, 2006. p. 26-55.

Recebido em: 20/04/2020.

Aceito em: 03/07/2020. 